\title{
Biopsychosocial determinants of wellbeing - a blueprint for tackling well-being inequalities?
}

\begin{abstract}
Kaz Stuart
Director of the Centre for Research in Health and Society, University of Cumbria. United Kingdom
\end{abstract}

\begin{abstract}
This paper argues for the 'social determinants of health' (SDoH) discourse to be extended in three respects. Firstly, the case is made for the 'social' aspect of SDoH to be extended to include biological, psychosocial and social determinants, leading to a new framing of the 'biopsychosocial' determinants of health. Secondly, the paper proposes the focus on health outcomes is extended to include all aspects of well-being, otherwise important interrelationships are overlooked, a shift to biopsychosocial determinants of well-being. The final proposal is to view the path of determinants as multi-directional rather than purely toward outcomes, as outcomes then become determinants themselves in complex cycles, rather than simple linearity. This leads to the final modelling of biopsychosocial cycles of well-being. The paper presents secondary data related to a fictional character to underpin the theoretical developments proposed, and concludes that these three extensions enable an expanded awareness of determinants of wellbeing, with promising implications for practice.
\end{abstract}

Keywords : Biopsychosocial, determinants, wellbeing, equity, social justice. 


\section{Introduction}

The prevalence of health and well-being inequalities is now well documented as an enduring issue by the decade apart publications by Sir Michael Marmot (2010; 2020), a situation now further laid plain by the 2020 Coronavirus pandemic which is further widening inequities (Office for National Statistics, 2020).

Rather than becoming embroiled in political or philosophical debates about equality and equity, this paper adopts a 'consequentialist' approach meaning that inequality is rejected due to the negative consequences it inflicts on certain groups of people (Jensen and Kersbergen, 2017: 21). The seriousness of the impact of these inequalities cannot now be denied though, and, as the World Health Organisation Commission on the Social Determinants of Health said; "Reducing health inequalities is .... an ethical imperative. Social injustice is killing people on a grand scale" (CSDH, 2008). Even from a fiscal point of view, the demand for greater equality is clear, the Marmot Review (2010) signposting that:

- $\quad$ Illness, lost taxes and lost productivity estimated annual cost of £31-33 billion

- Social security payments due to ill health estimated annual cost of $£ 20-30$ billion (Marmot, 2010).

This paper proposes three theoretical developments which lead to the further proposal of a practice framework to tackle such issues. The first proposal is to extend what is known as a 'social determinants' model to include biological, psychological, social and cultural determinants. The second is to expand from consideration of 'health' outcomes to a wider conceptualisation of 'wellbeing'. The final theoretical proposal is to expand to a complex rather than linear modelling of determinants throughout the life course. It is to these three proposals that we now turn before they are exemplified in case study data.

\section{Three Theoretical Proposals}

\section{Extending the Social Determinants of Health Perspective to a Biopsychosocial Determinant Perspective}

Two negative discourses are relatively prevalent in society. One is that people 'deserve' the outcomes they get, that poor health is due to poor choices (Elwell-Sutton et al., 2019). This is a part of the wider societal 'meritocracy' (Bloodworth, 2016). The second is that health is a matter of 'luck', some people have good luck and good outcomes whilst others do not. Both 
discourses individualise outcomes, making them the business of each individual person and their ability to make good choices or to be 'lucky' (Health Foundation, 2019). This individualistic focus negates the importance of society and the influence it may exert on individuals, groups and communities and enables individual blaming. This is not the only example, negative media coverage stirs public denouncement of immigrants, people living in poverty, the homeless, the addicted. The stories lead us to conclude that unpleasant outcome such as homelessness, poverty, drug addiction, even sexual exploitation are somehow deserved (Dorling, 2010, p.2). 'Fat shaming' (Gunnars, 2019) is a clear indicator of the individualising, meritocratic, blame oriented practice that ignores a wide range of factors which might influence a person to be overweight.

The SDoH perspective is a powerful counter to these negative discourses. Statistical measures and case study data have clearly demonstrated causal links between a range of social circumstances and health outcomes (Marmot, 2010; 2020). Returning to the example above, the influence of family norms, housing, availability of junk good, cost of good food, and presence of stress are now understood to have an influence on obesity (LCOBS, 2019). The SDOH perspective does not absolve people of responsibility but rather accounts for the role structures have in people's lives, it adds a structure to agency (Archer, 1995). This provides us with a balanced view of health as influenced by the structures of society and an individual's personal decisions.

The World Health Organisation (WHO) Commission on the Social Determinants of Health (CSDH) defines social determinants of health as the circumstances in which people are born, grow, live, work and age. These conditions are influenced by the distribution of money, power and resources operating at global, national and local levels (CSDH, 2008). Whilst various models may stress different social factors, what unites the SDoH theories is the idea of the influence of society on conditions of life and how these in turn affect health (Strother Ratcliffe, 2017). Societal factors might include levels of inequality, attitudes to people, stereotypes and social norms. These then 'allow' certain social conditions to prevail such as low levels of income, suitability of housing, neighbourhood safety, pollution, availability of work, stress in the workplace, transport, availability of healthy food and clean water and so on. Some models of SDoH focus on a narrow range of determinants. Ward, Mamerow and Meyer (2013), for example, used three categories of determinants; social inclusion, social empowerment and socio-economic security. Whilst these contain multiple measures, they 
miss many other factors and may therefore present a skewed vision of the impact of determinants, missing many important variables.

Dahlgren and Whitehead's (1991) model makes a range of determinants explicit, including socio-economic, cultural and environmental conditions, social and community networks, lifestyle factors and demographic and constitutional factors. These additional factors are helpful in expanding thinking about why a person is presenting certain issues. Perhaps taking these as read, the $\mathrm{SDoH}$ model shown in the CSDH (2008:51) report amalgamates psychosocial and biological factors within the same domain, which serves to obscure important nuances. Despite this, the SDoH perspective has created a vital evidence-based refocus on structural issues that lead to inequitable health outcomes. It is, however, a simple modelling and adopting a more complex view of determinants may be helpful. As Ekersley (2015:121) states the body of SDoH research to date appears to; "tell a simple, coherent and compelling story", and this may have overlooked much complexity.

Alongside the rise of the SDoH perspective is the biopsychosocial model, and this may add some of the nuance absent in the SDoH models. The biopsychosocial model was first developed by Engel in 1977 to counter the dominant biomedical model of illness (Engel, 1977). Since that time its popularity has increased, Wade and Halligan (2017:997) found the term biopsychosocial used as a keyword in titles in over 500 journal articles in 2016. The model is designed to complement rather than replace the biomedical model as a personcentred temporal approach enabling the identification of choices and limitations in the provision of 'care' or attainment of 'wellness' (Wade and Halligan, 2017:999, Bolton and Gillet, 2019; Engels, 1977).

Broadly speaking, the biopsychosocial (BPS) framework is grounded in complexity theory and general systems theory. The underpinning assumption is of a hierarchy of individual and interlinked systems affect health and wellbeing. By proposing the BPS model, Engel was refuting; the dualistic mind-body separation apparent in the medical model, reductionistic causal medical thinking and the impact of an observer on someone observed. All of these factors, he felt, dehumanised care. As a result, the BPS model adopted a 'broad definition' of the object of medical work in terms of illness - as concerned with the life world of the patient. This directs attention to all domains of human life, as the boundaries between health and illness, between well(ness) and sick(ness), are diffused by cultural, social, and psychological considerations (Farre and Rapley, 2017). As Engels (1960) stated: 
“"the existing biomedical model does not suffice. To provide a basis for understanding the determinants of disease and arriving at rational treatments and patterns of health care, a medical model must also take into account the patient, the social context in which he [sic] lives, and the complementary system devised by society to deal with the disruptive effects of illness, that is, the physician role and the health care system. This requires a biopsychosocial model" (p. 132).

The model has been implemented as a philosophy, approach and practice across a wide range of disciplines including; health education, health psychology, public health or preventive medicine, public opinion (Alonso, 2004); dementia, aging and pain (Gagliese et al., 2018); cardiology, oncology, general paediatrics, internal medicine, orthopaedics, obstetrics, gynaecology and adolescent health (Farre and Rapley, 2017:5-7); psychotherapy (Gilbert, 2019) and even gun crime (Hargarten et al., 2018). Indeed, it is perhaps most readily accepted into social welfare practices where complexity and sociological concepts underpin assumptions than into a clinical world with its positivistic philosophy.

The BPS model is not, however, without critique. Methodological criticisms focus on its lack of empirical evidence (Alvarez et al., 2012:179) and lack of 'testability' (Farre and Rapley, 2017:4). Linked to this is the lack of agreed criteria or measures for each factor (Farre and Rapley, 2017:4). Practically speaking some argue for the difficulty of implementing it in clinical practice (Alvarez et al., 2012:179; Benning, 2015:315), particularly as it is so general (Farre and Rapley, 2017:4; Ghaemi, 2009; McManus, 2005), and this is perhaps why it has remained a philosophy rather than a front line practice. From a cultural perspective it is criticised as failing to take account of the subjectivity of the individual and their cultural background (Benning, 2015:315). Theoretical criticisms focus on its lack of adherence to complexity theory (from where it originated) in that it does not acknowledge the impossibility of identifying all the factors at play in any complex phenomenon (Benning, 2015:315). And finally, Kontos (2011:509) claims an over enthusiasm on the part of clinicians in adopting and then clinging to the BPS 'straw man', which cannot solve all the issues in the medical system. Many of these claims, argue Farre and Rapley (2017:5), have been overcome by Smith et al's (2013) implementation of the philosophy practically in 'evidence based patient centred interview protocols'. These interview protocols place communication and complexity at the heart of all clinical interactions, they are data driven, controllable and practical. In this respect they overcome the methodological and practical critiques of the model and pragmatically situate it as the best tool to gain the best insight into the complexity of any one person. For 
them, the model is not about solving the issues of the medical system, but providing better care for people.

The BPS model was supported as a common health language by the World Health Organisation in 2002 and remains a prime model for preventative health care as it enables the starting point of health issues to be addressed earlier in the life course (Marmot, 2005) from a range of wider determinants. Some factors are predetermined at birth, for example, a range of biological factors are genetically determined such as our gender, race, and congenital health issues. Adding a biological range of determinants to the social determinants is therefore important. Psychosocial factors seek to understand the extent to which social conditions shape behaviours and attitudes. These factors are also known to exert a huge influence on health outcomes. Living alone, may lead to loneliness, for example, which has been shown to decrease life expectancy by $26 \%$ (Holt-Lunstad et al., 2015). Adding an acknowledgement of culture to the social determinants, as cultural norms are known to exert such influence on people (Ekersley, 2013:123). For example, living in a family who drink alcohol on a regular basis creates a strong cultural expectation that everyone in the family will drink, limiting the possibility for entirely 'free' choice. In this respect they are cultural factors are closely aligned with the risk and protective factor discourses, where risk factors exacerbate determinants, and protective factors insulate against determinants of outcomes (Currie et al., 2012:6). These are acknowledged widely in the Dahlgren and Whitehead model of SDoH (1991) but overlooked in the later WHO (2010) and Marmot (2010) reports. Expanding to a socio-cultural perspective on determinants therefore reveals additional nuance and complexity. These biological, psychosocial and sociocultural determinants are all important and need accounting for.

The different factors encompassed within each of these areas are shown in the table below, although there is much overlap between them.

Table One: Biopscyhosocial determinants

\begin{tabular}{|c|c|c|}
\hline Biological factors & Psychological factors & Sociocultural factors \\
\hline Genes & Life satisfaction & Education (attendance and \\
Age & Self-esteem & attainment) \\
Gender & Self-efficacy & Employment status \\
Ethnicity & Motivation & Financial and material resources \\
Congenital and acquired health & & Family status (separation, security, \\
\hline
\end{tabular}




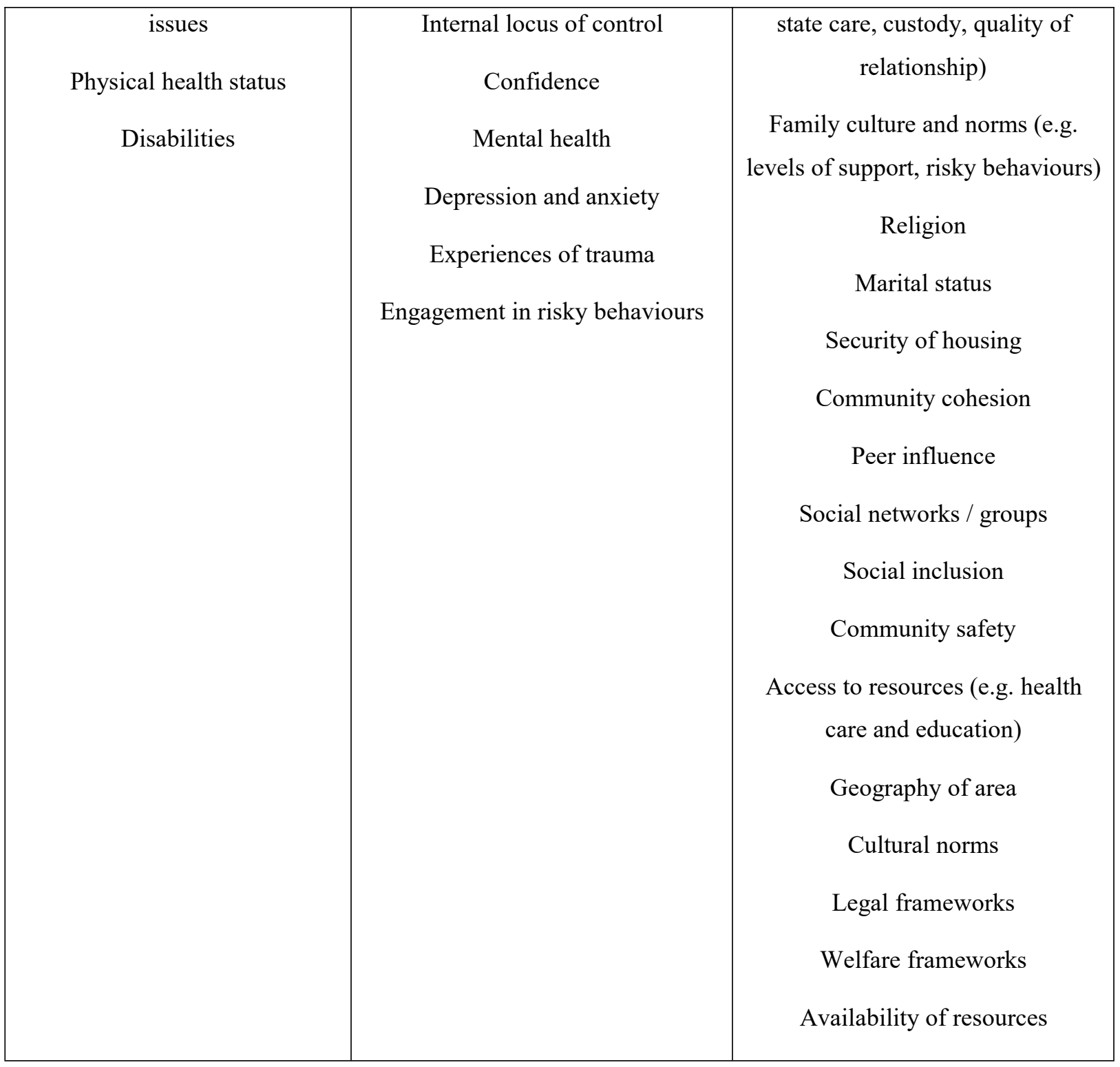

As argued by the WHO (2010) and Marmot (2010) these determinants sit within an economic, social and welfare policy framework. This may be felt as a cause for desperation as none of us may individually change the dominant political culture we live in. Whilst front line practitioners may not individually be able to improve income inequality or prejudice prevalent in society, they are able to take them into account when discussing the situations and options available to the person they are supporting. Not only does this support the practitioners awareness of how and why a person presents as they do, but if shared, it also develops the persons sense of who they are and what they can be. Developing awareness is framed as an important precursor to making choices and taking action (AUTHORS 2018). Understanding why you have asthma may be as important as knowing you have asthma, and being able to make informed choices to manage or improve it grounded in that knowledge better still. Living 40 miles away from an asthma clinic with poor public transport links is an important 
factor to consider, for example. From this perspective, the local, national and international context is important to acknowledge as it informs day to day decisions and actions. Just as the accumulation of positive and negative influences accumulates over a life time (Marmot, 2010), so do the positive and negative choices we make. For this reason, figure one shows the BPS factors embedded in their wider context.

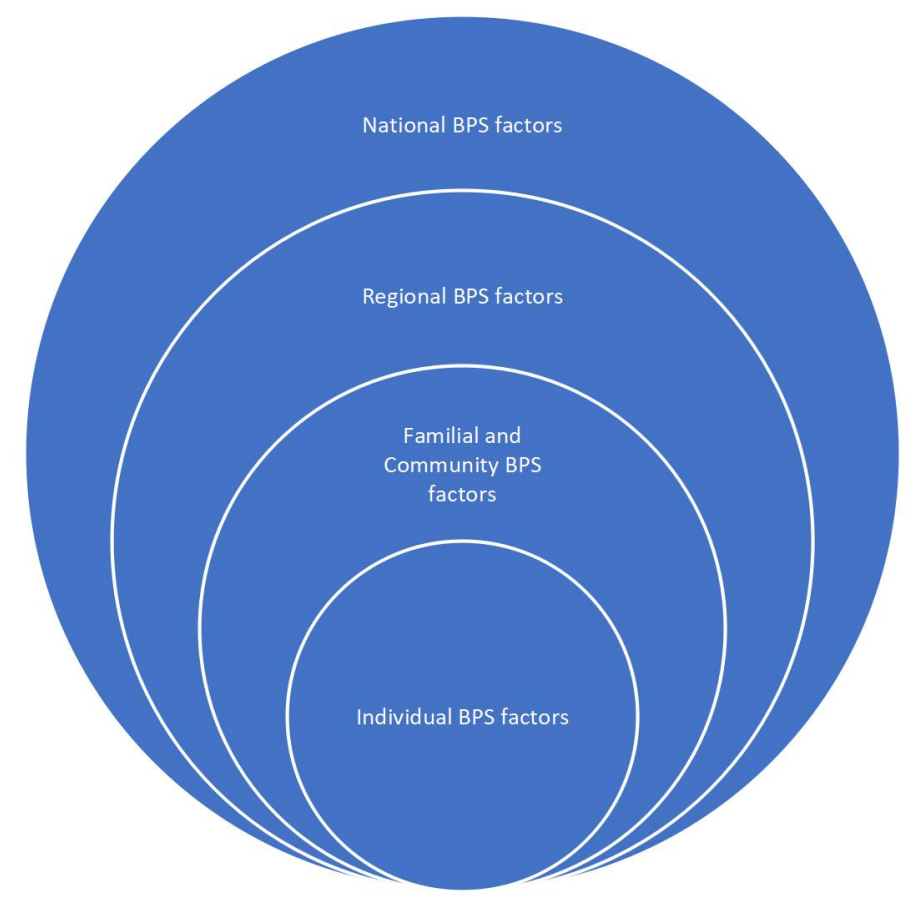

Figure One: A Biopscyhosociocultural Model of Determinants of Well-being

This model also takes account of regional and national inequities. Living in the north of England, for example, has been shown to reduce life expectancy by 18 years, and is an important (and unacceptable) regional biological factor to consider which might otherwise be overlooked. This modelling then, as well as providing a holistic view of health, also provides a rationale for people's health conditions and a comprehensive context within which to plan individual and population level health interventions. It could also be a powerful interdisciplinary tool - rather than health practitioners working on social determinants of health and teachers working on social determinants of education all sectors could work together across boundaries to address the complex and multifaceted nature of determinants conjointly. The BPS framework would therefore be particularly useful if adopted as a common framework to support wellbeing across health, education, social care and wider sectors. 


\section{Extending the Focus from Health to a Focus on Well-being.}

Whilst health care focuses primarily on enabling people to survive, physically and mentally function well and live a long life, a second factor is increasingly demanding attention: quality of life. Living a long time may not be 'enough' and we now have an expectation that we will live with a varying but overall good quality of life (Carr, Gibson and Robinson, 2001). Whilst health is a prime factor influencing the quality of life, so are social and emotional factors. Loneliness, for example are known to impact negatively on life expectancy as well as eroding a person's sense of meaning and enjoyment of day to day activities. A holistic view of quality of life (Evans, 1991) is therefore important. A more productive frame for the consideration of holistic outcomes and quality of life is well-being. Whilst predominantly adopted in the context of public health, well-being is useful as a holistic model across all health care settings, education, social care and other sectors.

There are multiple definitions of well-being from different disciplines, discourses and countries. These can broadly be considered to comprise a typology on dual axes of objective and subjective, and personal and social dimensions (AUTHORS, 2018:4). In line with the rest of this paper, a holistic and multi-dimensional position is adopted on well-being as; "feeling good and functioning well" (Aked et al., 2008:1-2) in order to keep well-being the concern of all practitioners. There are a range of benefits to adopting a well-being focus. The first is the granularity that a well-being focus lends to discussion of determinants whereas amalgamating well-being under the banner of health can obscure or reduce meaningful detail. Secondly the well-being discourse focuses attention on the paradigm of 'wellness' rather than illness which tends to be the foci of health (Helliwell, 2019).

Accounting for well-being alongside other measures of national growth (e.g. GDP) is becoming more popular (Diener et al., 2009; Dolan and Metcalfe, 2012) and has been endorsed by the Organisation for Economic Co-operation and Development (OECD, 2005). The UK has a Measuring National Wellbeing Programme (Office for National Statistics, 2010) which combines objective and subjective measures of well-being. Adding a social determinant perspective to these new data sets has been argued to have potential to inform future social policy (Deeming, 2013), but is currently lacking. The prevalence of well-being in policy terms does further support the use of adopting this approach, especially given how sophisticated this modelling is as discussed below.

The UK Measuring National Wellbeing Programme (Office for National Statistics, 2010) monitors ten domains of wellbeing and 43 associated indicators. Initially this was shown in a 
'wheel' format, however, this has since been replaced with a 'dashboard' displaying current levels and trends displayed across all 43 indicators. There is much to commend about this this transparent and longitudinal approach, however, there are also issues with the measures. Measures were mostly operationalised through an Annual Population Survey which elicited 320,000 responses last year (ONS, 2019). This is a relatively small sample, and one which is skewed to those motivated to complete and return a paper survey. Secondly, whilst comprehensive, there are some notable areas of wellbeing, or 'illbeing' omitted from the indicators with little rationale as to why, such as people experiencing abuse, people who are obese, people with addictions. What the wellbeing indicators do achieve, however, is a multidimensional approach to well-being, including life satisfaction, which could inform a more nuanced modelling of BPS determinants of not health, but well-being.

Well-being is the appropriate construct to use as it is associated with wider benefits in health including decreased risk of disease, illness and injury, improved immune function, recovery and increased longevity (Ostir, Markides and Black, 2000; Frederickson and Levenson, 1998). Other benefits of well-being include increased productivity at work, higher income and improved relationships (Tov and Diener, 2008; Lyubomirsky, King and Diener, 2005). The SDOH model (Solwar and Irwin, 2007) adopted in the 2008 Commission on Social Determinants of Health (2008:51) cite 'health and wellbeing' as the ultimate goal of their work (emphasis added). Equally, the Marmot Report (2010) aims to 'reduce health inequalities and improve health and well-being for all' (emphasis added). Yet both documents adhere to the convention of subsuming well-being within the wider discourse of health, rather than health being a contributory factor in well-being. Changing the focus to well-being opens up a wider inter-disciplinary space enabling health, education, social care, housing, employment and other sectors to see their role in addressing inequities.

\section{Extending to a Complex Rather than Linear Modelling of Outcomes}

It is well recognised that determinants of outcomes are initiated at birth and continue throughout the life-course (Graham, 2009). This not only adds a temporal nature to determinants, as they act throughout our lives, but also adds a cumulative perspective as we accumulate positive and negative effects throughout the life course (Marmot, 2010:42). This is now well theorised as a psychosocial process where stress from one set of poor determinants (or risk factors) create stress which further erodes other outcomes (Sapolsky, 2005:94), creating viscous cycles of disadvantage which may even be intergenerational. The same is true of certain behavioural choices, often promoted by stress, which then lead to 
further negative health outcomes. Loneliness, for example, may prompt drinking, leading to poor liver functioning. This in turn may lead to a further decline in health or life satisfaction, leading to other poor outcomes.

This discussion leads to the conclusion that determinants of health do not operate in simple lines of linear causality. The range of BPS factors at play in well-being interact with one another leading to a range of outcomes which further influence one another in complex looping (Braithwaite et al., 2018) or rhizomatic systems (Deleuze and Guatarri, 1987). Complex systems are deemed to be interlinked, interdependent and adaptive (Morrison, 2002:6), fuzzy, non-linear, and diffuse (Eckesley, 2015:122) which are all hallmarks of the SDoH discussed. Systems thinking, correspondingly, are characterised by multiple messy, imprecise journeys (Braithwaite et al., 2018), which further reinforces the qualities of the BPS model and its departure from positivism. Complexity science, evolving itself from these preliminary fields considers the relationships between elements.

Rather than a single professional considering how they might improve the attainment of a child in school, complexity science and the BPS model would encourage a consideration of home life, family life, cultural norms in that area, peer group, genetics, health, nutrition, mental health and so on. None of these would be singularly responsible for improving attainment and nor would the teacher be singularly responsible for improving them. But with other professionals, working across these domains could dramatically improve the child's attainment and so looking ahead, life chances. Whilst the 'Every Child Matters' (DfES, 2005) agenda was short lived, its intentions were perhaps well placed in encouraging all professionals to work together to improve outcomes for all children. The proposal is, therefore that understanding the BPS cycles of well-being, as shown in figure two, is an appropriate route to reducing inequities (Braithwaite et al., 2018:5). 


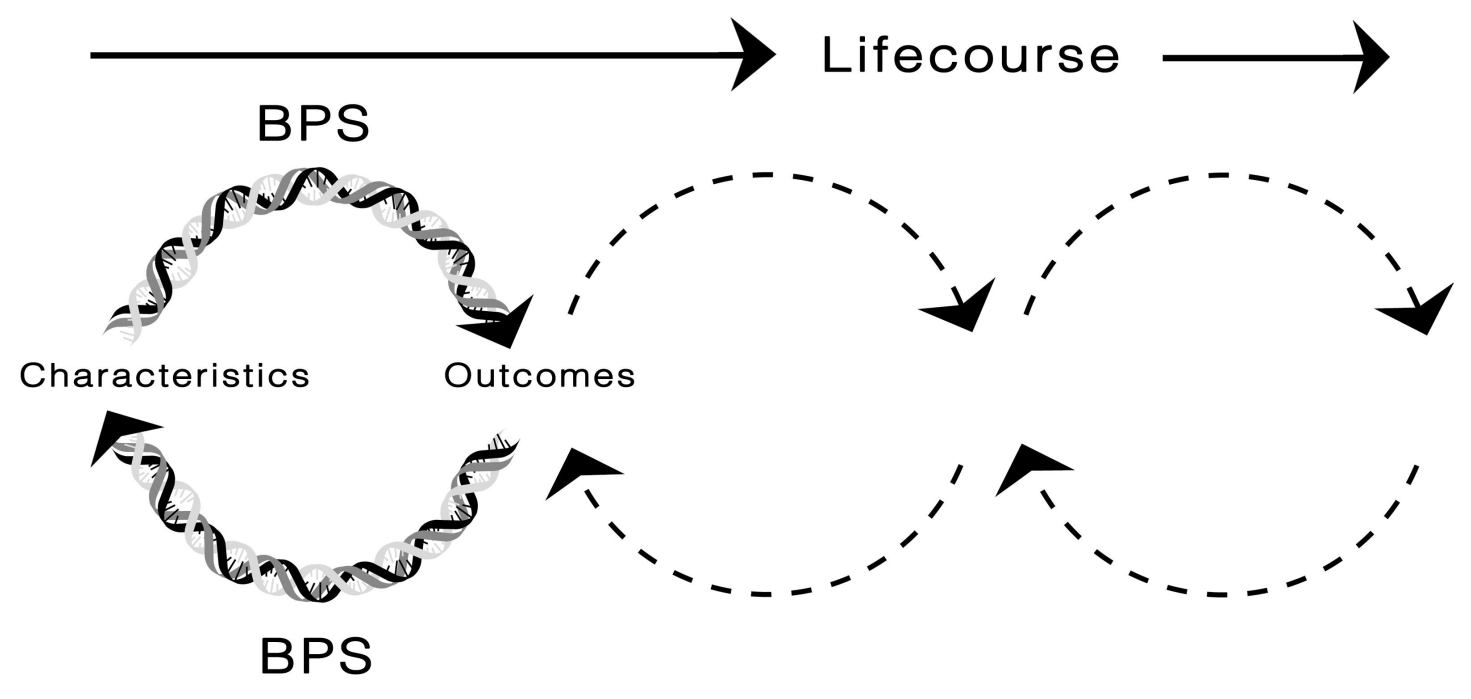

Stuart (2020) The Biopsychosocial Life Course Process.

Figure Two: Biopsychosocial Cycles of Well-being

\section{Methods}

This paper draws on a data set collected in a research project to understand the scale and nature of the impact of Covid-19 on people's lives. This data set is used as illustrative of the complexity of 'wellbeing' issues and of the three central arguments of this paper. Working within a mixed methods paradigm (Brannen, 2005) in order to add conceptual clarity and coherence to this key area of knowledge (Niglas, 2000). Participants were sought through a range of networks and social media platforms hence there was no specific inclusion criteria. They were asked to share their personal experiences via three broad questions:

What was your life like before the pandemic?

What was the impact of the pandemic on your life?

What support do you need to recover?

Such open-ended questions enabled the participants to determine the length and depth of their answers; consequently, submissions varied from a few sentences to 500-wordsData collection began on March 15th, 2020 and by June 29th, 2020, 305 participants had responded.

The ethical considerations took account of institutional guidance and relevant social media research guidance (Social Media Research Group, 2016). Ethical permission was granted by the University of Cumbria Ethics Committee. Participant consent was secured via the JISC 
Online Survey participant information and consent section. All narratives were anonymised for analysis with email addresses securely stored on an encrypted device to ensure withdrawal was possible and any safeguarding concerns followed up or referred on to relevant professionals.

The data was abductively analysed (Tavory and Timmermans, 2014) using a pre-existing biopsychosocial framework which was iteratively developed. First, data was coded into biological, psychological or social categories. Second, coding moved from simple categorization to thematic and analytical, with new codes being developed to capture the richness of the data. Last, the frequency of each theme was counted to 'quantisise' the narratives (Wojatzki et al., 2018).

The participants were primarily female $(n=231)$, aged 45-65 years old $(n=157)$, with preexisting health conditions $(n=189)$ and lived with a partner or spouse $(n=216)$, in a house (213) with garden (121), located in Northern England (55); most had hobbies and reported participating in and sports. No participant disclosed their ethnicity which may suggest being predominantly White British. This sample bias suggests the findings very generally showed the impact of COVID-19 on people who are mature, with social support, space, occupation and a relatively high socioeconomic status. As such, the findings present a story from a position of relative advantage; providing insights, if not information, into the impact that might be experienced by those less well off.

\section{Findings}

The full scope of the research findings from this project is beyond this paper. Rather a few illustrative examples are provided to illustrate the inter-relationship and complexity of BPS factors involved in well-being and how they operate cyclically.

Biological factors were important. 189 respondents had a pre-existing health issue, of whom 42 reported experiencing a worsening in their condition. Examples included, a respondent with diabetes whose "blood sugar levels [had] become erratic" (P.6), and another with irritable bowel syndrome whose: "tummy is telling me I'm more anxious than usual!" (P.8). Three people disclosed that treatments or operations had been delayed, which might also impact their health adversely, for example: 
"I have regular injections... These have been suspended for three months. This will compromise my immune system and make me more vulnerable to catching the virus" (P.21). “[I've] been suffering with shortness of breath and pain for 6 weeks now, I need a lung function test and CT scan, but it was cancelled just as the virus took hold" (P.30).

This illustrates that health issues can be compounded by the social context we live in - in this instance prolonged low level stress and isolation from social distancing.

The immediate impacts of the new 'covid-19' context affected behavioural choices which could, secondarily, affect health status longer term. For example, some participants $(n=35)$ commented on changes in their health choices and lifestyle. The most frequent was eating more $(n=10)$, perhaps driven by extended periods at home: "I am overeating more due to having time to cook and bake" (P.129), although four people mentioned healthier eating due to having more time to cook. No one mentioned eating less. Furthermore, ten people reported exercising less, whilst six mentioned exercising more due to being furloughed. For some people however, diet and exercise factors compounded: "I'm snacking more and exercising less" (P.256). This illustrates the cyclical nature of BPS factors in chains of complex causality. The psychological impacts of the pandemic were very apparent. Eight states of mental wellbeing were reported; six negative and two comparatively positive. Generalised anxiety was the most frequently mentioned state of negative mental wellbeing $(n=84)$, followed by stress $(n=51)$, depression $(n=33)$, and general poorer mental wellbeing $(n=18)$, although some reported feeling a combination of these. For example: one respondent reported "Increased stress, anxiety and depression. Huge feelings of uncertainty and some fear" (P.3); another had "waves of anxiety [and] stress [and] worry for the future, personally for self [and] family, [and] for my business [and] employees" (P.271); whilst a third experienced "lower mood and feelings of worthlessness" (P.301). Loneliness was reported by 24 people living alone; for most $(n=19)$ loneliness was a negative experience, making them "Feel very isolated and vulnerable" (P.189). Only five people mentioned feeling happy in their own company: "I enjoy my own company and like peace and quiet, so I am enjoying being locked down" (P.295). A poor health status and living alone increased people's likelihood of poor mental wellbeing illustrating the influence biological and social factors can have on psychological outcomes.

Social changes were wide reaching and mostly involving loss of normality. One example of a social impact are changes to work practices. Most respondents commented on changes to 
employment ( $\mathrm{n}=295)$; whilst only nine respondents had lost their employment, 40 had been furloughed, 18 had experienced changes to working hours, and 5 had been redeployed. The nature of work was also changing, sometimes in terms of responsibilities $(n=25)$, but also in other respects such as diminished work life balance $(n=39)$ : “The difference between work and personal time has blurred into one" (P.265); and increased workload pressure (n=29). Moreover, benefits from less commuting $(n=16)$ were tempered by the strain of increased digital meetings $(\mathrm{n}=14)$ : "I am working at home but needing to work long hours with back to back meetings with no breaks" (P.15). Only four people felt their work-life balance had improved and only six felt their workload had decreased. Additionally, a few people reported feeling unsafe at work due to exposure to COVID-19 $(n=4)$ or due to a lack of PPE $(n=5)$. The socio-economic context has therefore increased the risk of psychological issues albeit through worry about employment status, stress from online working, or fear at a lack of PPE. Prolonged mental health issues may then go on to negatively impact on health status longer term.

These examples of data from a larger project illustrate the key arguments laid out in this paper. Firstly, they show that social determinants play a part in health status, and indeed the inequitable way in which Covid-19 affects the elderly, poor and BAME populations is well known (CITE?). Secondarily, the data illustrates that Covid-19 is not just a health issue, but has a range of biological, psychological and social components and outcomes, justifying the use of a BPS modelling. Thirdly, the impacts are not just health related and so an understanding of well-being is important. Finally, this data shows that one impact may become the cause of another outcome in on-going cycles. In this respect we need to understand people as having varying levels of well-being which are complex and dynamic and involve ongoing cycles of BPSfactors.

This paper has argued for an expansion of the social determinants of health into a wider consideration of the BPS determinants of well-being. This expansion enables much greater awareness of how and why people experience the outcomes they do, and what choices, enabled and constrained by structures, are on offer to them, and range of factors that need to be supported in order to improve well-being. This is as important for the practitioner as the individual or group. This expanded and complex awareness offers important lines of inquiry into well-being for multi-practitioners to explore with individuals and groups this may be at the level of extended holistic conversations with a person - health practitioners asking about home life, employment and finance, and teachers asking about health and so on. This not only 
opens up potential for the individual practitioner to support people more broadly, but also reinvigorates the promise of integrated working in the context of well-being development practice. Expanding services and roles with hybrid professionals and boundary crossing have been common in the last decade and this too is perhaps evidence of the need to step out of silos and to consider well-being holistically.

\section{Conclusion}

This paper has made three proposals; to extend what is known as a 'social determinants' model to include biological, psychological, social and cultural determinants; to expand from consideration of 'health' outcomes to a wider conceptualisation of 'wellbeing', and to adopt a complex rather than linear modelling of determinants throughout the life course.

These three proposals have been linked to the critical practice framework for wellbeing development which enables individuals, groups, practitioners and organisations to foster increased awareness of their current situation (and BPS determinants of it), to make choices (using their agency whilst enabled and constrained by structures) and to act in ways which will support well-being as a holistic, multi-disciplinary and complex concept.

This paper drew on secondary data pertaining to Covid-19 to demonstrate its plausibility and recommends that at the most basic level this may inform the ways in which a practitioner talks to a person they are supporting and at its most complex could serve to reconfigure services into integrated well-being hubs. An analysis of people's assets and needs seems fruitful through a biopsychosocial lens, but no previous studies have been found which analyse practice in a similar vein to see how biopsychosocially informed they are, and this is an important avenue for future research.

\section{References}

[1] Aked, J., Marks, N., Cordon, C., Thompson, S. (2008). Five Ways to Wellbeing: The Evidence. London: nef

[2] Alonso Y. (2004). The biopsychosocial model in medical research: The evolution of the health concept over the last two decades, Patient Education and Counseling 53: 239-244. 
[3] Alvarez A.S., Pagani M., Meucci P. (2012). The clinical application of the biopsychosocial model in mental health: a research critique, American Journal Physical Medical Rehabilitation, 2012; 91(suppl):173-180.

[4] Archer, M. (1995). Being Human. Oxford: Oxford University Press.

[5] Benning, T. (2015). Limitations of the biopsychosocial model in psychiatry, Advances in Medical Education and Practice, 2015 (6): 347-352.

[6] Bloodworth, J. (2016). The Myth of Meritocracy. Cambridge: Biteback Publications.

[7] Bolton, D., Gillet, G. (2019). The Biopsychosocial Model of Health and Disease: New Philosophical and Scientific Developments. Cham (CH): Palgrave Pivot.

[8] Braithwaite, J., Churruca, K., Long, J.C., Ellis, L.A., Herkes, J. (2018). When complexity science meets implementation science: a theoretical and empirical analysis of systems change, BMC Medicine, 16(63).

[9] Brannen, J. (2005). Mixed Methods Research a Discussion Paper, NCRM Methods Review Papers, London: NCRM.

[10] Carr, A.J., Gibson, B., Robinson, P.G. (2001). Measuring quality of life: Is quality of life determined by expectations or experience? British Medical Journal. 322(7296):12401243. doi:10.1136/bmj.322.7296.1240

[11] CSDH (2008). Closing the Gap in a Generation. Health equity through action on the social determinants of health. Final Report on Social Determinants of Health. Geneva: World Health Organisation.

[12] Currie, C., Zanotti, C., Morgan, A., Currie, D., de Looze, M., Roberts, C., Samdal, O., Smith, O.R.F., Barnekow, V. (2012). Social Determinants of Health and Well-Being Among Young People. Health Behaviour in School-Aged Children Study. International Report from the 2009/2010 Survey. Copenhagen: World Health Organisation.

[13] Deeming, C. (2013). Addressing the Social Determinants of Subjective Wellbeing: The Latest Challenge for Social Policy, Journal of Social Policy, 42(3): 541-565.

[14] Deleuze, G., Guattari, F. (1987). A Thousand Plateaus. Capitalism and Schizophrenia. Minessota: Minessota Press.

[15] Diener, E. (2009). Assessing Well-Being. The Collected Works of Ed Diener. Dordrecht: Springer.

[16] Dolan, P., Metcalfe, R. (2012). Measuring subjective wellbeing: recommendations on measures for use by national governments, Journal of Social Policy, 41(2): 409:407. 
[17] Dorling, D. (2010). Injustice. Why social inequality persists. Bristol: Policy Press.

[18] Elwell-Sutton, T., Marshall, L., Bibby, J., Volmert, A. (2019). Briefing: Reframing the Conversation on the Social Determinants of Health. London: The Health Foundation.

[19] Engel, G.L. (1960). A unified concept of health and disease, Perspect. Biol. Med. 1960, 3, 459-485.

[20] Engel, G.L. (1977). The need for a new medical model: a challenge for biomedicine, Science, 196: 129-136.

[21] Evans, R.W. (1991). Quality of Life, Lancet, pp.338-363.

[22] Farre, A., Rapley, T. (2017). The New Old (and Old New) Medical Model: Four Decades Navigating the Biomedical and Psychosocial Understandings of Health and Illness, Healthcare, 5(88): pp.1-9.

[23] Frederickson, B.L., Levenson, R.W. (1998). Positive emotions speed recovery from the cardiovascular sequelae of negative emotions. Cognition and Emotion, 12:191-220.

[24] Gagliese, L., Gauther, L.R., Narain, N., Freedman, T. (2018). Pain, aging and dementia: towards a biopsychosocial model, Progress in Neuropsychopharmacology, (2018), pp.207-215.

[25] Ghaemi, S.N. (2009). The rise and fall of the biopsychosocial model, The British Journal of Psychiatry, 195(1):3-4.

[26] Gilbert, P. (2019) Psychotherapy for the 21st Century: An integrative, evolutionary, contextual, biopsychosocial approach, Psychology and Psychotherapy: Theory, Research and Practice, 92:164-189.

[27] Graham, H. (2009). Understanding Health Inequalities, $2^{\text {nd }}$ Edition. Maidenhead: Open University Press.

[28] Gunnars, K. (2019). The Harmful Effects of Fat Shaming, Healthline, February $27^{\text {th }} 2019$. Accessed 16/5/20 at https://www.healthline.com/nutrition/fat-shaming-makes-thingsworse

[29] Hargarten, S.W., Lemer, E.B., Gorelick, M., Brasel, K., deRoon-Cassini, T., Kohlbeck, S. (2018). Gun Violence: A biopsychosocial Disease, Western Journal of Emergency Medicine: Integrating Emergency Care with Population Health, 19(6): 1024-1043.

[30] Health Foundation (2019). Public Perceptions of Health and Social Care. London: The Health Foundation. 
[31] Heliwell J.F. (2019). Determinants of Well-Being and Their Implications for Health Care, Annals of Nutrition and Metabolism, 74(2):8-14.

[32] Holt-Lunstad, J., Smith, T.B., Baker, M., Harris, T., Stephenson, D. (2015). Loneliness and social isolation as risk factors for mortality: a meta-analytic review, Perspectives on Psychological Science, 10(2), pp.227-37.

[33] House of Commons Library (2018). NEET: Young People Not in Education, Employment or Training. Accessed at https://researchbriefings.parliament.uk/ResearchBriefing/Summary/SN06705

[34] Jenson, C., Kersbergen, C.J. (2017). The Politics of Inequality. London: Palgrave Macmillan.

[35] Kontos, N. (2011). Biomedicine - Menace or Straw Man? Re-examining the Biopsychosocial Argument, Academic Medicine, 86: 509-515.

[36] Lyubomirsky, S., King, L., Diener, E. (2005). The benefits of frequent positive affect: does happiness lead to success? Psychol Bulletin, 131(6):803-855.

[37] Marmot, M. (2005) Remediable or preventable social factors in the aetiology and prognosis of medical disorder. In P.D. White (Ed.) Biospsychosocial Medicine: An Integrated Approach to Understanding Illness. New York: Oxford University Press, pp.39-58.

[38] Marmot, M., Allen, J., Goldblatt, P., Boyce, T., McNeish, D., Grady, M., \& Geddes, I. (2010). Fair society, healthy lives: Strategic review of health inequalities in England post 2010. Accessed 24.12.19 at www.instituteofhealthequity.org/projects/fair-societyhealthy-lives-the-marmot-review

[39] Marmot, M., Allen, J., Boyce, T., Goldblatt, P., Morrison, J. (2020). Health Equity in England: the Marmot Review 10 Years On. Accessed 31.3.20 at https://www.health.org.uk/publications/reports/the-marmot-review-10-years-on

[40] AUTHORS, 2018

[41] McManus, C. (2005). Engel, Engels, and the side of the angels, The Lancet, 395(9478): 2169-2170.

[42] Morrison, K. (2002). School Leadership and Complexity Theory. London: Routledge.

[43] LCOB (2020). The London Childhood Obesity Strategy. London's Child Obesity Taskforce: London. 
[44] Niglas, K. (2000). Combining quantitative and qualitative approaches, Paper presented at the European Conference on Educational Research, 20.

[45] OECD (2005). Beyond GDP. World Forum Statistics, Knowledge and Policy Proceedings. Paris: OECD.

[46] Office for National Statistics (2019). Measures of National Well-Being Dashboard. $\begin{array}{llll}\text { London: } & \text { ONS. } & \text { Accessed }\end{array}$ https://www.ons.gov.uk/peoplepopulationandcommunity/wellbeing/articles/measuresofna tionalwellbeingdashboard/2018-04-25

[47] Office for National Statistics (2020). Covid-19 and Deprivation in the UK. London: ONS.

[48] Ostir, G.V., Markides, K.S., Black, S.A. (2000). Emotional well-being predicts subsequent functional independence and survival. J Am Geriatr Soc , 48:473-478.

[49] Sapolsky, R. (2005). Sick of Poverty, Scientific American, 293(6):92-99.

[50] Social Media Research Group (2016). Using Social Media for Social Research: An Introduction. London: Government Social Research Unit.

[51] Solwar, O., Irwin, A. (2007). A Conceptual Framework for Action on the Social Determinants of Health. Discussion Paper for the Commission on Social Determinants of Health. Geneva, World Health Organisation.

[52] Smith, R.C.; Fortin, A.H.; Dwamena, F.; Frankel, R.M. (2013). An evidence-based patient-centered method makes the biopsychosocial model scientific. Patient Educ. Couns. 2013, 91, 265-270.

[53] Strother Ratcliff, K. (2017). The Social Determinants of Health: Looking Upstream. Cambridge: Polity Press.

[54] Tavory, I., Timmermans, S. (2014). Abductive Analysis: Theorising Qualitative Research. Chicago: University of Chicago Press.

[55] Tov, W., Diener, E. (2008). The well-being of nations: Linking together trust, cooperation, and democracy. In: BA Sullivan, M Snyder, JL Sullivan (Eds.) Cooperation: The psychology of effective human interaction. Malden, M.A.: Blackwell Publishing; $323-342$.

[56] Wade, D.T., Halligan, P.T. (2017). The biopsychosocial model of illness: a model whose time has come, Clinical Rehabilitation, 31(8): 995-1004. 
[57] Ward, P., Mamerow, L., Meyer, S.B. (2013). Identifying Vulnerable Populations Using a Social Determinants of Health Framework: Analysis of National Survey Data across Six Asia-Pacific Countries, PLoS ONE, 8(12): e83000.

[58] Wojatzki, M., Mohammad, S., Zesch, T., Kiritchenko, S. (2018). Quantifying Qualitative Data for Understanding Controversial Issues, Proceedings of the Eleventh International Conference on Language Resources and Evaluation (LREC 2018), May 2018; Miyazaki, Japan, European Language Resources Association (ELRA).

[59] World Health Organisation (2002). Towards a Common Language for Functioning, Disability and Health. Brussels: WHO. 